\title{
Particle Size and Particle Size Distribution of Suspension Polymerization of Methyl Methacrylate in Baffled Tank Reactor
}

\section{R.M. Mohsen and Y.M. Abu-Ayana}

Polymers \& Pigments Department, National Research Centre, Cairo, Egypt.

\begin{abstract}
USPENSION polymerization is commonly used to produce micron-sized $(10-100 \mu \mathrm{m})$ polymer beads, in which the final particle size distribution is an important end-use property. A laboratory reactor was designed and constructed in the author's previous article to study the effect of both speed of agitation and concentration of suspension stabilizer on particle size and particle size distribution during the suspension polymerization of methyl methacrylate. In this article, scaling up of the laboratory reactor was done in order to find out the effect of change of the baffled tank reactor dimensions on the relation between particle size and both speed of agitation and stabilizer concentration. It was found that there were contradictions of the effect of speed of agitation on the particle size from the previous results. New empirical equations correlating the average particle size and particle size distribution (PSD) were derived from this study.
\end{abstract}

Keywords: Suspension polymerization,Poly methyl methacrylate (PMMA), Polystyrene (PS), Polyvinyl chloooride (PVC), Particle size distribution (PSD).

Suspension polymerization processes ${ }^{(1)}$ are commercially important for the production of polymer beads having wide applications such as chromatographic separations and ion-exchange resins. A wide spread fragments applicability of microparticles in different fields ${ }^{(2)}$ including medical, textile, cosmetics, pesticide, printing industry and pharmaceutical. Novel molecularly fragments imptinted polymers -membranes, microspheres, and photoswitchable particles ${ }^{(3)}$. Microporous polymer beads for chemical decontamination ${ }^{(4)}$. The particle size distribution (PSD) may appreciably influence the performance of the final product; therefore, the evaluation of (PSD) is a major concern in the design of a suspension polymerization process. The most important factors in the practical operation of suspension polymerization ${ }^{(5)}$ is the control of the final particle size and particle size distribution. Many research studies have indicated that the particle size distribution is a result of the dynamic equilibrium between breakage and coalescence of the monomer droplets. An important limitation in the development of the microparticles is the difficulty to control particle size. Variation of droplet size during the whole polymerization process under the unsteady stirring condition, compared with that under a steady stirring condition, was found to be small ${ }^{(6)}$. Some of the variables affecting the particle size (PS) and the particle size distribution (PSD) in suspension polymerisation ${ }^{(7.8)}$ are : 
1. Type, molecular weight, and concentration of suspension stabilizer.

2. Agitation rate and agitator design, reactor design, and position

3. Water-monomer

4. Reaction tempererature

5. Reaction time, type, and concentration of the radical initiator

6. Type and concentration of monomer

7. Effect of additional surfactant, electrolyte, and/or viscosity improvment

8. Ratio of initial monomer viscosity to aqueous phase viscosity

9. The Reynolds and Webber Number.

Some of the technologies used in evaluating particle size are sieve analysis ${ }^{(9,10)}$, coulter counter, and microscopy.Polacco ${ }^{(11)}$ studied the measurments of particle size distribution during suspension polymerization. A scanning electron microscope was employed to show the spherical nature of particles. Near infrared reflectance spectroscopy (NIRS) may be used efficiently for in-line evaluation of average particle size in suspension polymerization ${ }^{(12)}$. Measurement of particle distribution in suspension polymerization was done using in situ laser backscattering ${ }^{(13)}$.

A suspension polymerization process that generates narrow-size distribution and spherical particles in the range of $3-10 \mu$ was described by Kamiyama ${ }^{(14)}$. Santos et $a l .{ }^{(5)}$ also studied, the effect of agitation speed and stabilizer concentration on particle size distribution in laboratory scale styrene suspension polymerization reactors . Preparation of magnetic polystyrene with a narrow (PSD) was carried out ${ }^{(15)}$.

Parameters affecting the final particle size and the particle size distribution under unsteady stirring conditions, such as the agitation speed and the periodic interval also have been studied in details ${ }^{(16)}$ and the results were compared with those under a steady stirring condition. Suspension polymerization used for the production of polymer particles with diameters in the range of $50-750 \mu \mathrm{m}$ was studied $^{(17)}$

The particle size distribution of the particles produced in batch suspension polymerization was calculated using a population balance model ${ }^{(18,19)}$. Studies were carried out to develop a mathematical model based on experimental results to correlate agitation and other polymerization parameters with particle size of polystyrene $^{(6,15,20)}$, polyvinyl chloride (PVC) ${ }^{(21)}$ and polymethyl methacrylate ${ }^{(11)}$. Effect of mixing process on the (PSD) and the mean diameter on thiol-triacrylate microcapsules was studied ${ }^{(2)}$.

A baffled laboratory scale reactor( $1 / 4$ liter capacity) with a flat paddle agitator ${ }^{(21)}$ had been previously designed (by the present authors) to investigate the effect of the impeller speed and the suspension stabilizer concentration on the average PS and PSD of PMMA particles).

In this article, scaling up of the laboratory reactor to two liter capacity was done in order to find out the effect of the baffled tank size on the relation between speed of agitation and stabilizer concentration on PS and PSD.

Egypt. J. Chem. 58, No. 4 (2015) 


\section{Experimental}

The baffled tank reactor of the same authors was enlarged to 2 liter with nearly the same geometrical dimensions to find out the effect of the speed of agitation and stabilizer concentration on PS and PSD.

\section{Apparatus}

A laboratory scale reactor (Fig. 1) was designed and constructed from stainless steel. It consisted of two parts, a cylindrical kettle of two liters capacity and a cover with a flat paddle agitator. The cover has four bolted upwards and downwards deflecting baffles, and two holes, one in which a glass condenser was fitted to condense any escaping monomer and the other in which a thermometer was fitted. The following geometric dimensions are fixed throughout the whole batches:

Hight of the tank $\mathrm{H}_{\mathrm{t}}=$ diameter of tank $\mathrm{D}_{\mathrm{t}}=130 \mathrm{~mm}$

Hight of tank $\mathrm{H}_{t}$ Hight of liquid $\mathrm{H}_{\mathrm{L}}=1.4$

Diameter of impeller $\mathrm{D}_{\mathrm{i}}=90 \mathrm{~mm}$

Blade $\mathrm{Wi}=10 \mathrm{~mm}$

Elevation of impeller above tank bottom $\mathrm{Z}=31 \mathrm{~mm}$

Width of baffles $\mathrm{W}_{\mathrm{b}}=10 \mathrm{~mm}$

Number of baffles $=4$

$\mathrm{H}_{\mathrm{L}} / \mathrm{D}_{\mathrm{i}}=1.4 \quad \mathrm{D}_{\mathrm{t}} / \mathrm{D}_{\mathrm{i}}=1.4$

$\mathrm{Z} / \mathrm{D}_{\mathrm{i}}=0.34 \quad \mathrm{~W}_{\mathrm{i}} / \mathrm{D}_{\mathrm{i}}=0.11$

$\mathrm{W}_{\mathrm{b}} / \mathrm{W}_{\mathrm{i}}=0.11$

It must be realized that any change in the geometrical arrangement affects considerably the particle size.

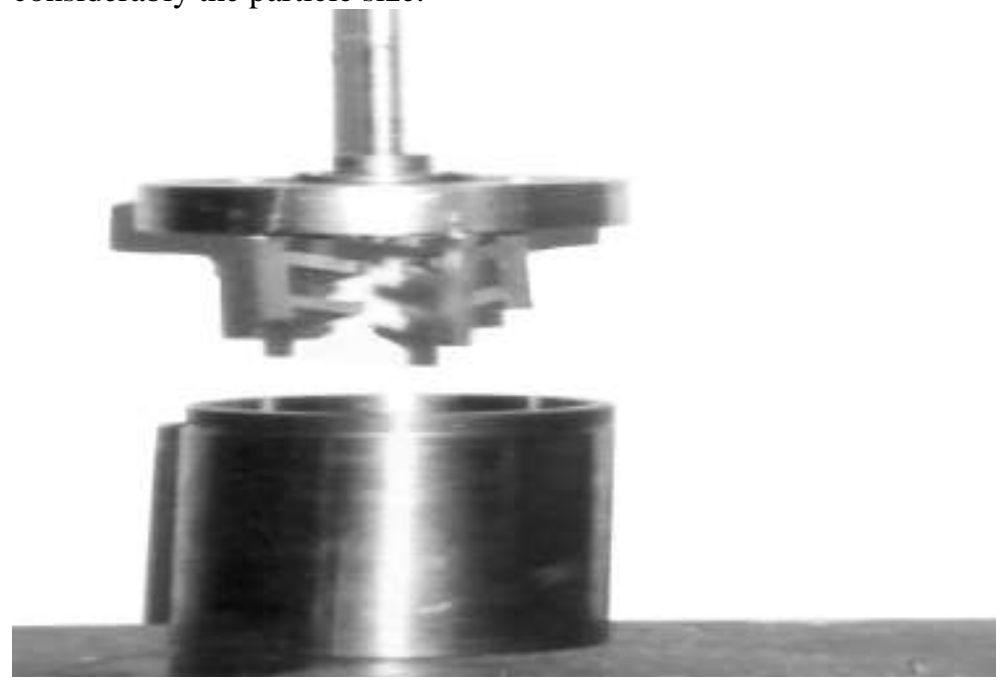

Fig. 1. Laboratory scale baffled reacto. 


\section{Technique}

Distilled water and soluble starch stabilizer were charged in the kettle; which was put in a thermostatically controlled water bath at $80^{\circ} \mathrm{C}$ and the impeller was worked at the intended speed, $\mathrm{N}$, which was measured periodically throughout the time of reaction by a speedometer. When the agitation became regular, methyl methacrylate monomer containing benzoyl peroxide was added. The reactant amounts are given in Table 1.

The time/temperature and speed of agitation were recorded periodically throughout the whole reaction. The gel stage was clearly observed by the rise of $\approx 5-8^{\circ} \mathrm{C}$ above the constant reaction temperature. Much care should be taken at this stage, since the increase in viscosity may slow down the agitator causing the polymer particles to coagulate. After the gel stage has been safely accomplished, the temperature went down again to normal value such that no danger of coagulation since the polymer beads with their smooth surfaces had already been formed. After one hour, the reaction was nearly completed, heating and agitation were stopped, and the product was left to settle down followed by decantation of liquid, washing, and drying. A sieve analysis was performed to classify the product into grades of narrow PSD. The average PS of each experiment was determined from the sieve analysis according to method $1^{(9)}$.

\section{Materials}

The materials used, classified under water phase and monomer phase, are given in Table 1.

TABLE 1. Reactants amounts .

\begin{tabular}{|c|l|}
\hline Water phase & Monomer phase \\
\hline 1106 gm water & 578 gm MMA \\
15.25 gm Na$_{2} \mathrm{HPO}_{4}$ & $2.899 \mathrm{gm} \mathrm{BZ}_{2} \mathrm{O}_{2}$ \\
0.406 gm NaH$_{2} \mathrm{PO}_{4}$ & \\
$\mathrm{~S} \mathrm{gm} \mathrm{soluble} \mathrm{starch}$ & \\
\hline
\end{tabular}

$\mathrm{S}=$ variable amount of soluble starch.

Method $1^{(9)}$

Cumulative weight percent retained on is plotted against equivalent diameter of each two successive sieves on a log-log paper. The average particle size $\mathrm{D}_{50 \%}$ was determined; also $\mathrm{D}_{16 \%}$ and $\mathrm{D}_{84 \%}$ cumulative weight retained on were determined. The dispersion and skew were calculated according to the following equations:

$$
\begin{gathered}
\text { Dispersion }=\left(D_{84 \%}-D_{16 \%}\right) / 2 \\
\text { Skew }=\left[\left(D_{84 \%}-D_{50 \%}\right)-\left(D_{50 \%}-D_{16 \%}\right)\right] /\left(D_{84 \%}-D_{16 \%}\right)
\end{gathered}
$$

The following notations will be found:

$\mathrm{X}=$ weight fraction retained on each sieve.

$\%$ cumulative weight retained on sieves $=\mathrm{X} /$ total weight.

$\mathrm{D}_{\mathrm{av}}=$ equivalent diameter of each two successive sieves.

Egypt. J. Chem. 58, No. 4 (2015) 
$D_{m}=$ average particle size in accordance to measurements of the particle size by method1

$\mathrm{D}_{16 \%}=$ particle size at $16 \%$ cumulative weight retained on.

$\mathrm{D}_{50 \%}=$ average particle size at $50 \%$ cumulative weight retained on.

$\mathrm{D}_{84 \%}=$ particle size at $84 \%$ cumulative weight retained on.

$\mathrm{PSD}=$ particle size distribution.

$\mathrm{N}=$ speed of agitation in rpm

$\mathrm{C}=$ concentration of soluble starch

\section{Results and Disscusion}

\section{Factors affecting the gel stage}

Though the suspension polymerization seems to be simple, the practical control of the reaction conditions is quite difficult, since tendency to coagulation of the globules is a considerable factor, which leads to the deterioration of the batch .The gel stage which can be considered the bottle neck in suspension polymerization reaction needs special care since the excessive heat of polymerization evolved at this stage produces a temperature rise of $5-8^{\circ} \mathrm{C}$ above the normal reaction temperature. Agitation will help distributing this heat and would prevent local overheating.

Two sets of experiments were performed in order to study the effects of agitation rate and starch concentration on the average particle size and PSD of the product.

TABLE 2. Relation between the concentration of starch and gel formation time at $480 \mathrm{rpm}$.

\begin{tabular}{|c|c|}
\hline \% Concentration of starch & Time (min.) \\
\hline 0.75 & 75 \\
1.00 & 75 \\
1.25 & 80 \\
1.50 & 75 \\
1.70 & 75 \\
1.756 & 75 \\
\hline
\end{tabular}

TABLE 3. Relation between the concentration of starch and gel formation time at $580 \mathrm{rpm}$.

\begin{tabular}{|c|c|}
\hline \% Concentration of starch & Time of gel formation,(min.) \\
\hline 0.795 & 125 \\
1.00 & 115 \\
1.24 & 110 \\
1.50 & 110 \\
\hline
\end{tabular}


TABLE 4. Relation between the speed of agitation and gel formation time at $1 \%$ concentration of starch.

\begin{tabular}{|c|c|}
\hline $\begin{array}{c}\text { Speed of agitation } \\
(\mathbf{r p m})\end{array}$ & Time,(min) \\
\hline & \\
460 & 75 \\
500 & 80 \\
560 & 105 \\
660 & 155 \\
\hline
\end{tabular}

TABLE 5. Relation between the speed of agitation and gel formation time at $1.5 \%$ concentration of starch.

\begin{tabular}{|c|c|}
\hline $\begin{array}{c}\text { Speed of agitation } \\
\text { (rpm) }\end{array}$ & Time, (min) \\
\hline & \\
480 & 75 \\
580 & 110 \\
680 & 155 \\
780 & 195 \\
& \\
\hline
\end{tabular}

Tables $2 \& 3$, show that the gel stage formation time is independent of the concentration of starch, while Tables $4 \& 5$ represents the dependence of the time of attaining the gel stage on the speed of agitation at constant concentrations of starch. It is proportionally increase with speed of agitation.

There are relations between speed of agitation $\mathrm{N}$ and stabilizer concentration $\mathrm{C}$ on the particle size and particle size distribution.

The speed of agitation N (400-900 rpm) at constant concentration of starch $(1-1.5 \% \mathrm{C})$ has an effect on PS and PSD.

Figures $2 \& 3$ show the cumulative plots retained on sieves against average diameter at 1 and $1.5 \%$ starch concentration, at variable agitation rate.

From Fig. 2 and 3, Tables 6 and 7 were obtained which summarize the variation of $\mathrm{D}_{16 \%}, \mathrm{D}_{50 \%}$ and $\mathrm{D}_{84 \%}$, dispersion and skew with the speed of agitation $\mathrm{N}$ at 1 and $1.5 \% \mathrm{C}$, respectively. 


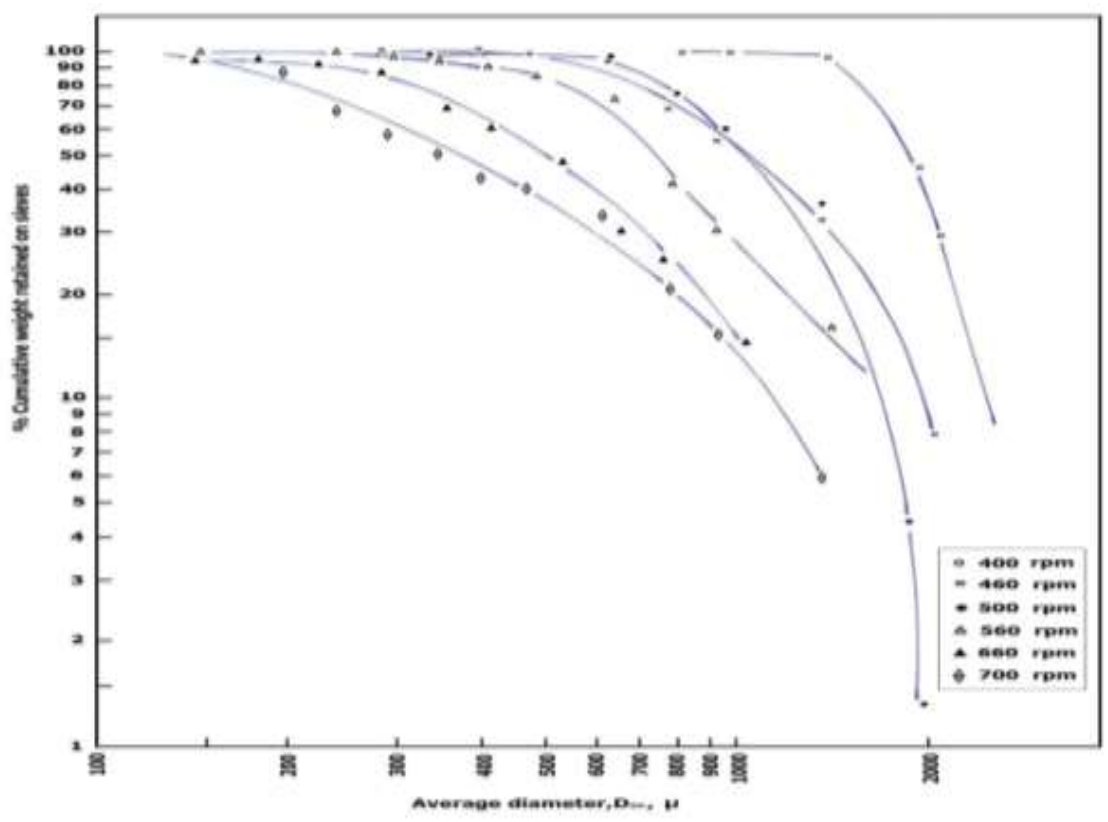

Fig. 2. Cumulative plot of sieve analysis PMMA using 1\% starch comcentration at variable speed of agitation.

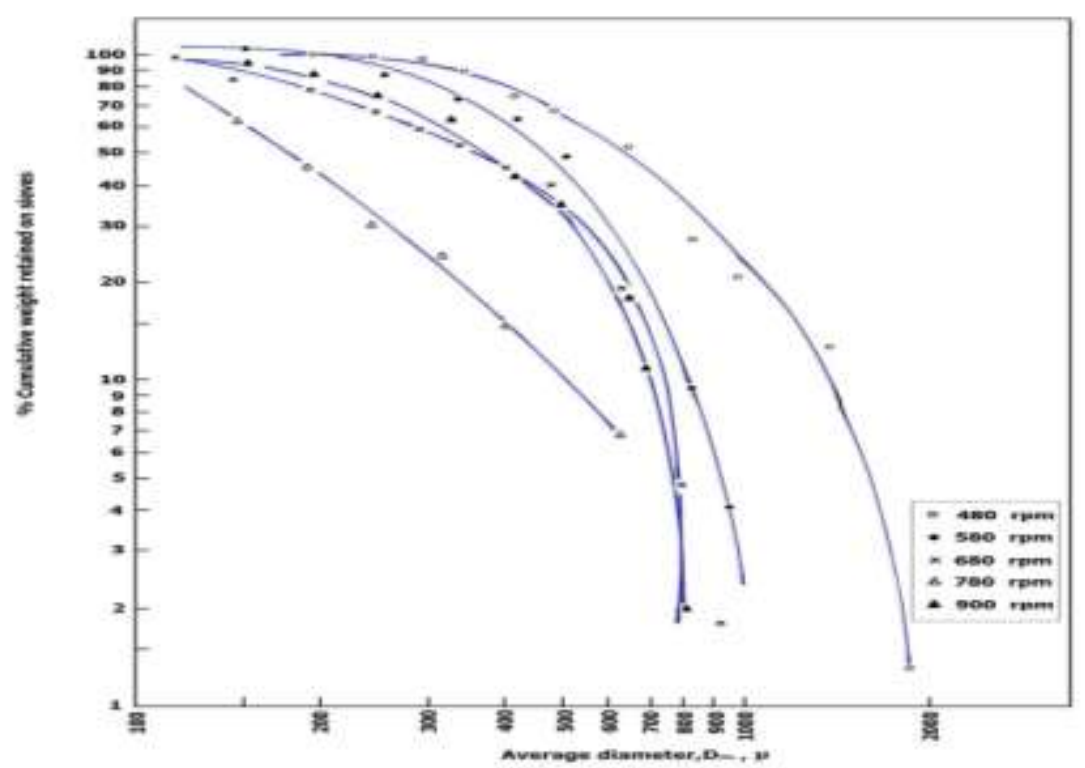

Fig. 3. Cumulative plot of sieve analysis PMMA using $1.5 \%$ starch comcentration at variable speed of agitation. 
TABLE 6. Variation of $D_{16 \%}, D_{50 \%}$ and $D_{84 \%}$, dispersion and skew with the speed of agitation $(\mathrm{N})$ at $1 \% \mathrm{C}$.

\begin{tabular}{|c|c|c|c|c|c|}
\hline $\mathbf{N}_{\mathbf{r p m}}$ & $\mathbf{D}_{\mathbf{1 6 \%}}$ & $\mathbf{D}_{\mathbf{5 0} \%}$ & $\mathbf{D}_{\mathbf{8 4} \%}$ & Dispersion & Skew \\
\hline 400 & 1500 & 1800 & 2200 & 350 & 0.1429 \\
460 & 640 & 1050 & 1720 & 540 & 0.2407 \\
500 & 720 & 1020 & 1600 & 440 & 0.3182 \\
560 & 375 & 570 & 1215 & 420 & 0.5357 \\
660 & 260 & 470 & 980 & 360 & 0.4167 \\
700 & 175 & 350 & 900 & 362.5 & 0.5172 \\
\hline
\end{tabular}

TABLE 7. Variation of $D_{16 \%}, D_{50 \%}$ and $D_{84 \%}$, dispersion and skew with the speed of

\begin{tabular}{|c|c|c|c|c|c|}
\hline \multicolumn{7}{|c|}{ agitation (N) at $\mathbf{1 . 5} \% \mathbf{C}$. } \\
\hline $\mathbf{N}_{\mathbf{r p m}}$ & $\mathbf{D}_{\mathbf{1 6 \%}}$ & $\mathbf{D}_{\mathbf{5 0} \%}$ & $\mathbf{D}_{\mathbf{8 4} \%}$ & Dispersion & Skew \\
\hline 480 & 350 & 600 & 1160 & 405 & 0.3827 \\
580 & 240 & 430 & 840 & 300 & 0.3567 \\
680 & 180 & 347.5 & 665 & 242.5 & 0.3093 \\
780 & 105 & 213 & 525 & 210 & 0.4857 \\
900 & 185 & 340 & 620 & 217.5 & 0.2874 \\
\hline
\end{tabular}

Tables 6 and 7 show that as the speed of agitation increases, the particle size decreases. The skew in Table 7 decreases indicating that $\mathrm{D}_{84 \%}$ approaches $\mathrm{D}_{50 \%}$. Plotting $\mathrm{D}_{16 \%}, \mathrm{D}_{50 \%}$ and $\mathrm{D}_{84 \%}$ against $\mathrm{N}$ at 1 and $1.5 \% \mathrm{C}$ on $\log -\log$ paper, the curves in Fig. 4 \& 5 are obtained.

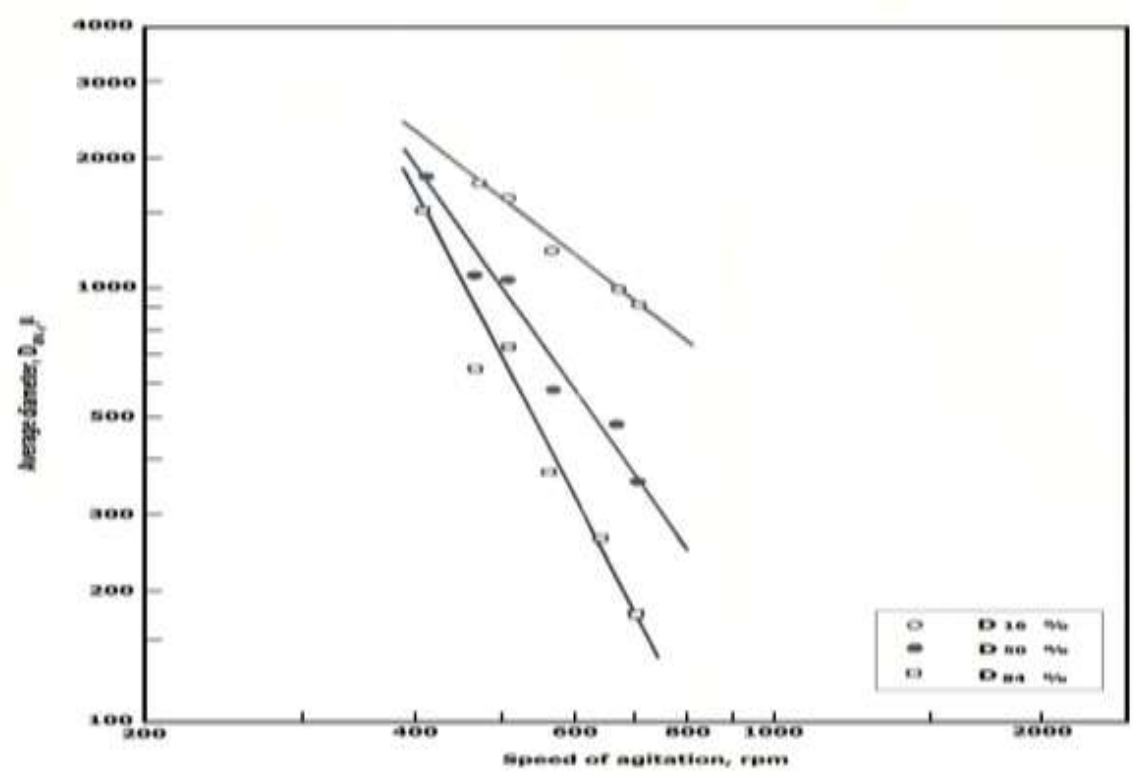

Fig. 4. Log average diameter as function of log speed of agiration at $1 \%$ starch concentration .

Egypt. J. Chem. 58, No. 4 (2015) 


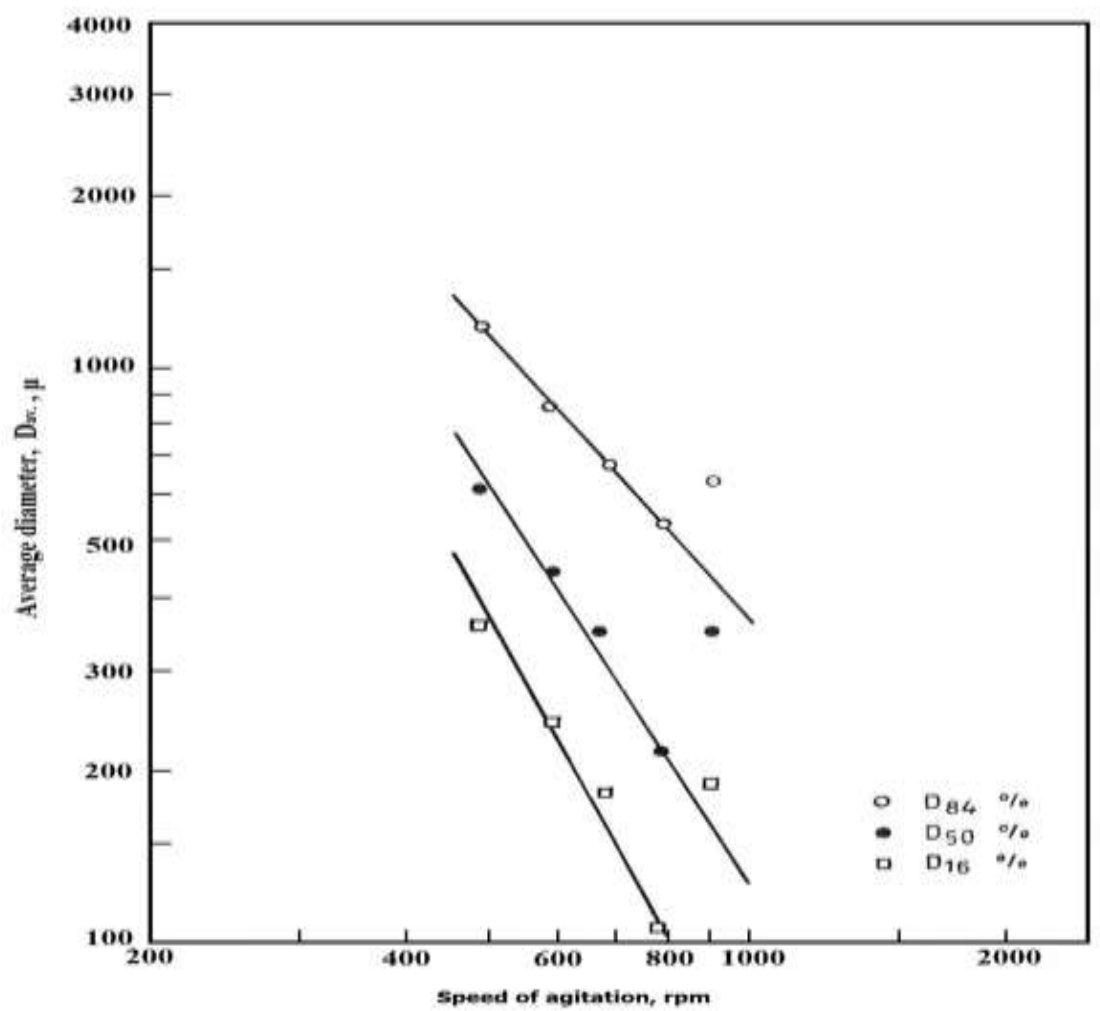

Fig. 5. Log average diameter as function of log speed of agiration at $1.5 \%$ starch concentration .

It is shown that $\log \mathrm{D}_{16 \%}, \log \mathrm{D}_{50 \%}$ and $\log \mathrm{D}_{84 \%}$ are inversely proportional to $\log \mathrm{N}$ and the relation may be governed by the equation:

$$
\log \mathrm{D}=\mathrm{A}+\mathrm{B} \log \mathrm{N}
$$

where A nd B are constants depending on starch concentration. This result contradicts with the previous results on the $(1 / 4 \mathrm{t}$ capacity reactor) in which the the particles size was directly proportional lt the speed of agitation. This contradiction in results was attributed to the prevailing of coalescence of polymer droplets over their breakage in the small reactor especially in the gel stage, this coincides with both Langner et al. ${ }^{(22)}$ who worked in a conventional stirred tank reactor at a speed of agitation of $\mathrm{N}>450 \mathrm{rpm}$, and Tanaka and Hosogai $^{(23)}$ who worked at a circular loop reactor at a speed of agitation $1300<$ $\mathrm{N}<1800 \mathrm{rpm}$. Scaling up of the rector allows liter capacity reactor permit water will absorb the heat of polymerization efficiently, accordingly the breakage of the globules prevails their coalescence. 


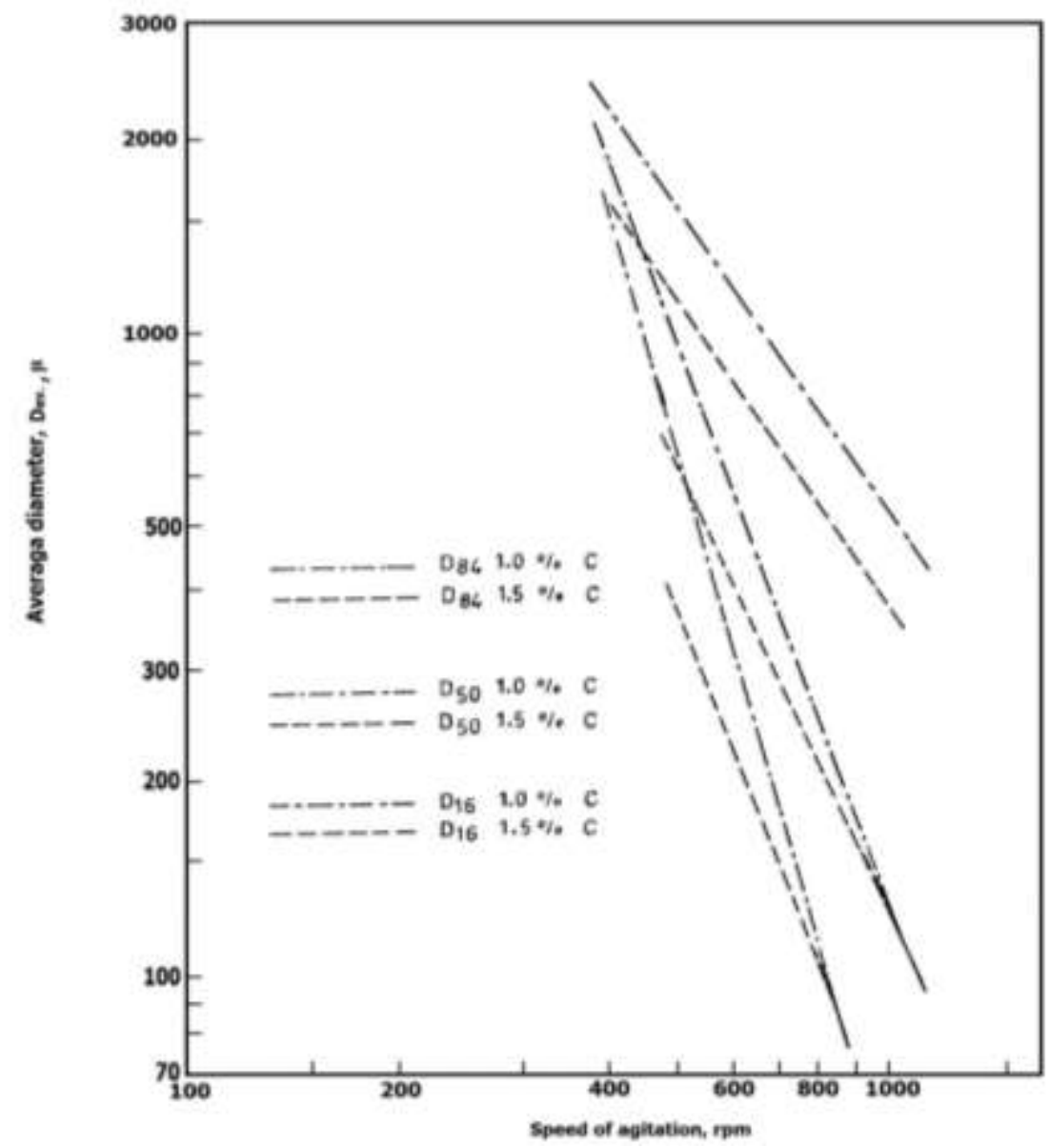

Fig. 6. Log average diameter as function of log speed of agiration at $1.5 \%$ starch concentration .

From Fig. $4 \& 5$, Fig. 6 is obtained which shows that as the speed of agitation increases, the corresponding curves for $\mathrm{D}_{16 \%}, \mathrm{D}_{50 \%}$ approach each other till they intersect at a specific point. At this point of intersection the $\mathrm{D}_{16 \%}, \mathrm{D}_{50 \%}$ has constant values independent of starch concentration.

Effect of the concentration of starch $C(0.75-1.75 \%)$ at constant speed of agitation $N$, on the PS and PSD.

Figures $7 \& 8$ show the cumulative plots retained on sieves against average diameter at 480 and $580 \mathrm{rpm}$, respectively, at variable starch concentrations.

Egypt. J. Chem. 58, No. 4 (2015) 


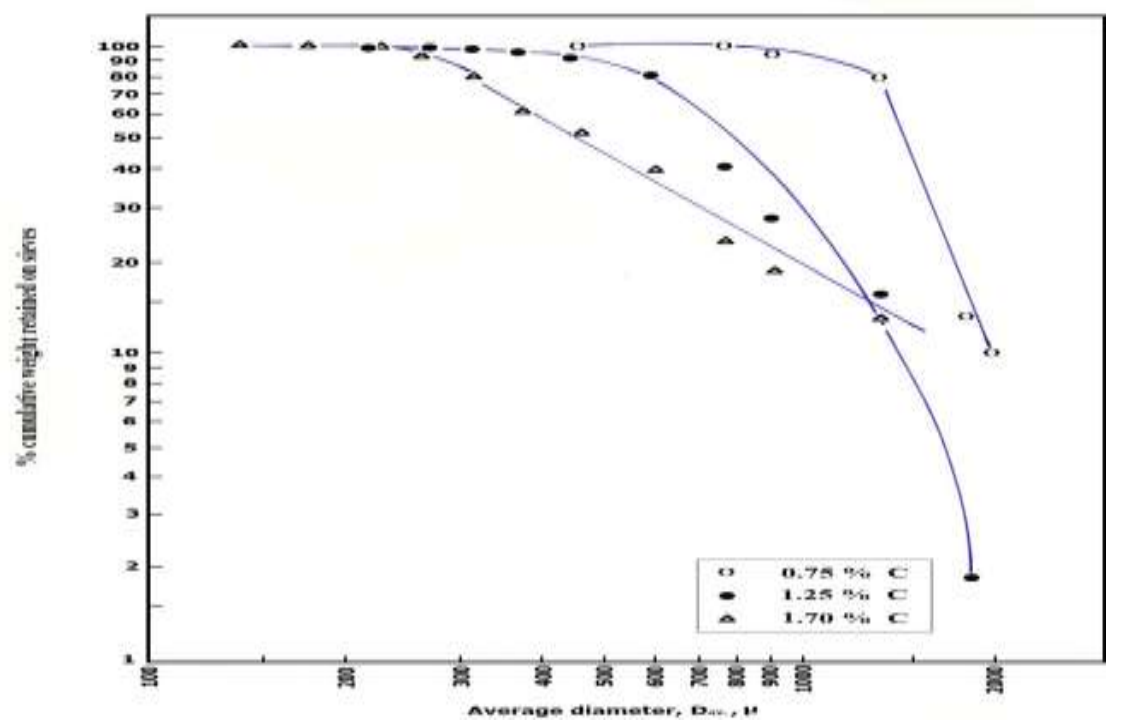

Fig. 7. Cumulative plot of sieve analysis PMMA using $480 \mathrm{rpm}$ speed at variable starch comcentration.

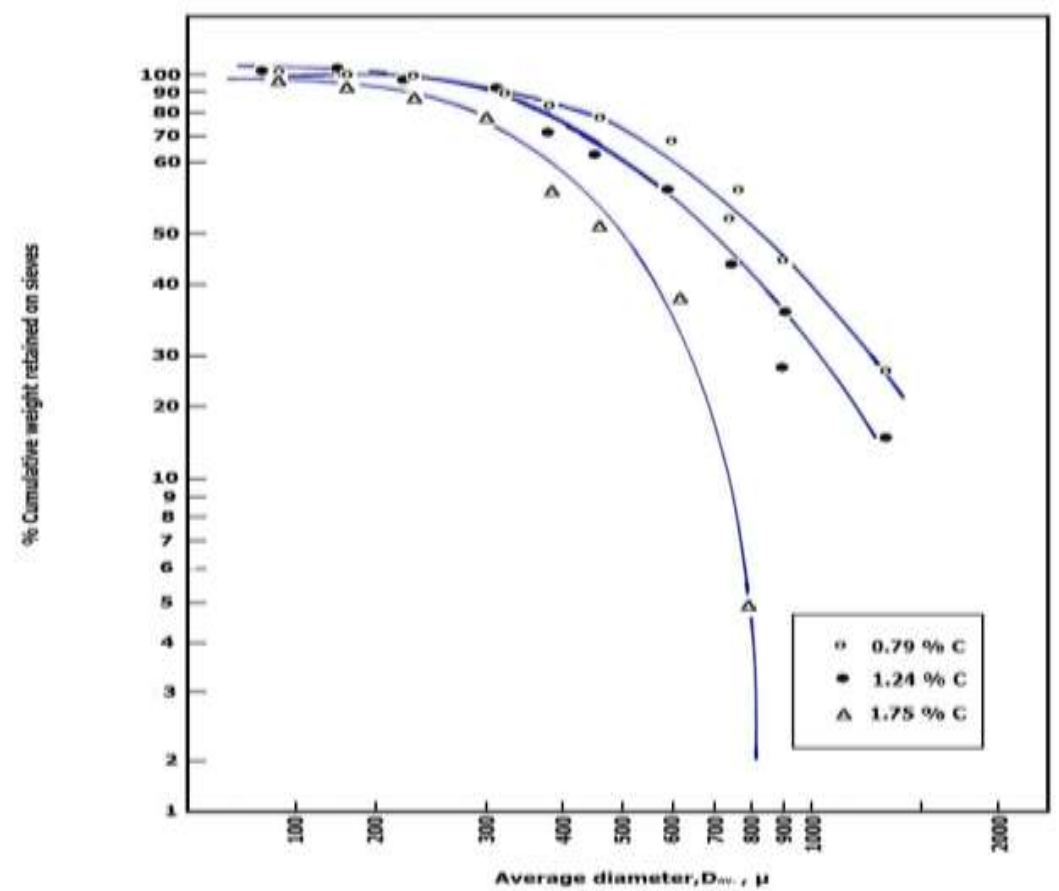

Fig. 8. Cumulative plot of sieve analysis PMMA using $580 \mathrm{rpm}$ at variable starch comcentration .

Egypt. J. Chem. 58, No. 4 (2015) 
From Fig. 7 and 8, Tables 8 and 9 were obtained which summarize the variation of $\mathrm{D}_{16 \%}, \mathrm{D}_{50 \%}$ and $\mathrm{D}_{84 \%}$, dispersion and skew with the starch concentration (C) at $480 \mathrm{rpm}$ and $580 \mathrm{rpm}$, respectively.

TABLE 8. Variation of $D_{16 \%}, D_{50 \%}$ and $D_{84 \%}$, dispersion and skew with the starch concentration( C) at $480 \mathrm{rpm}$

\begin{tabular}{|c|c|c|c|c|c|}
\hline $\mathbf{C}_{\boldsymbol{\%}}$ & $\mathbf{D}_{\mathbf{1 6 \%}}$ & $\mathbf{D}_{\mathbf{5 0} \%}$ & $\mathbf{D}_{\mathbf{8 4} \%}$ & Dispersion & Skew \\
\hline 0.755 & 1240 & 1450 & 1800 & 280 & 0.2500 \\
1.00 & 730 & 1050 & 1650 & 460 & 0.3043 \\
1.25 & 550 & 810 & 1250 & 350 & 0.2575 \\
1.50 & 350 & 600 & 1160 & 405 & 0.3827 \\
1.70 & 295 & 450 & 1180 & 442.5 & 0.6497 \\
1.75 & 325 & 480 & 1080 & 377.5 & 0.5894 \\
\hline
\end{tabular}

TABLE 9. Variation of $D_{16 \%}, D_{50 \%}$ and $D_{84 \%}$, dispersion and skew with the starch concentration( C) at $580 \mathrm{rpm}$.

\begin{tabular}{|c|c|c|c|c|c|}
\hline $\mathbf{C}_{\boldsymbol{\%}}$ & $\mathbf{D}_{\mathbf{1 6 \%}}$ & $\mathbf{D}_{\mathbf{5 0 \%}}$ & $\mathbf{D}_{\mathbf{8 4} \%}$ & Dispersion & Skew \\
\hline 0.79 & 385 & 705 & 1410 & 512.5 & 0.3756 \\
1.00 & 355 & 600 & 1200 & 422.5 & 0.4201 \\
1.242 & 340 & 585 & 1150 & 405 & 0.4012 \\
1.50 & 240 & 435 & 846 & 385 & 0.4545 \\
1.75 & 265 & 390 & 660 & 197.5 & 0.3671 \\
\hline
\end{tabular}

Tables $8 \& 9$ show that on increasing the starch concentration, the particle size decreases. Table 8 shows that both the dispersion and the skew increases with increasing $\mathrm{C}$. Plotting $\mathrm{D}_{16 \%}, \mathrm{D}_{50 \%}$ and $\mathrm{D}_{84 \%}$, against $\mathrm{C}$ in $\log -\log$ paper, the curves in Fig. 9 \& 10 are obtained.

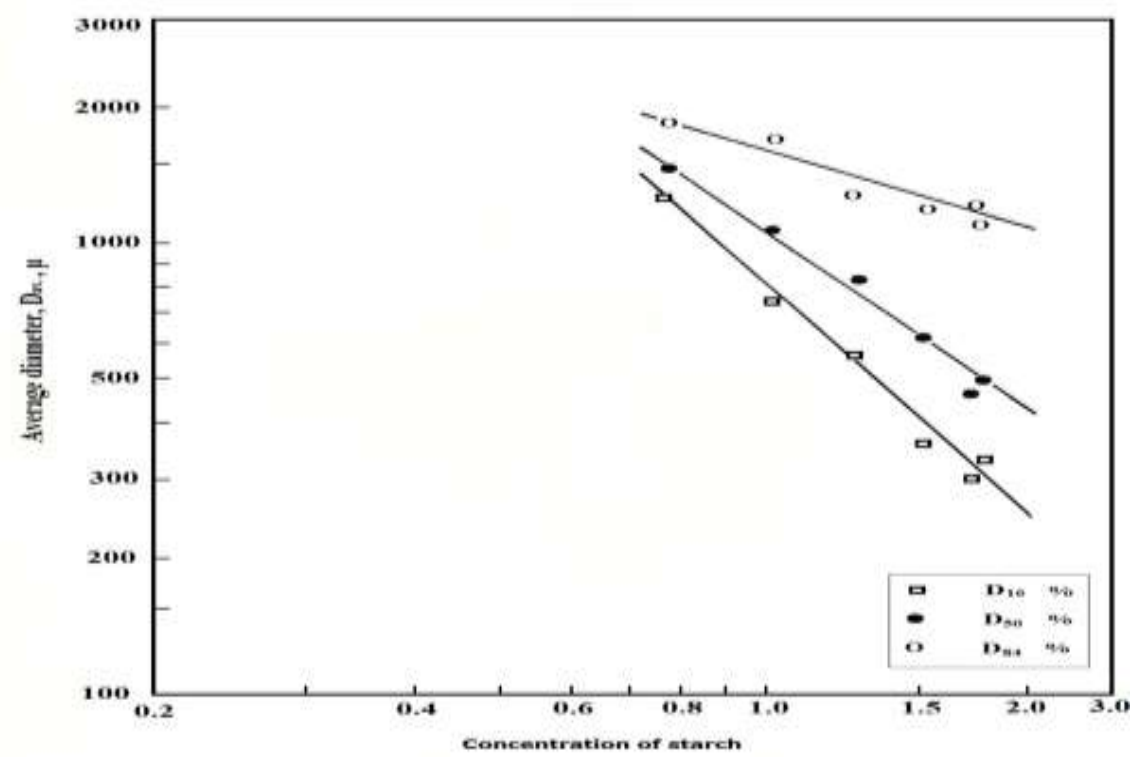

Fig. 9. Log average diameter as function of log concentration of starch at $480 \mathrm{rpm}$.

Egypt. J. Chem. 58, No. 4 (2015) 


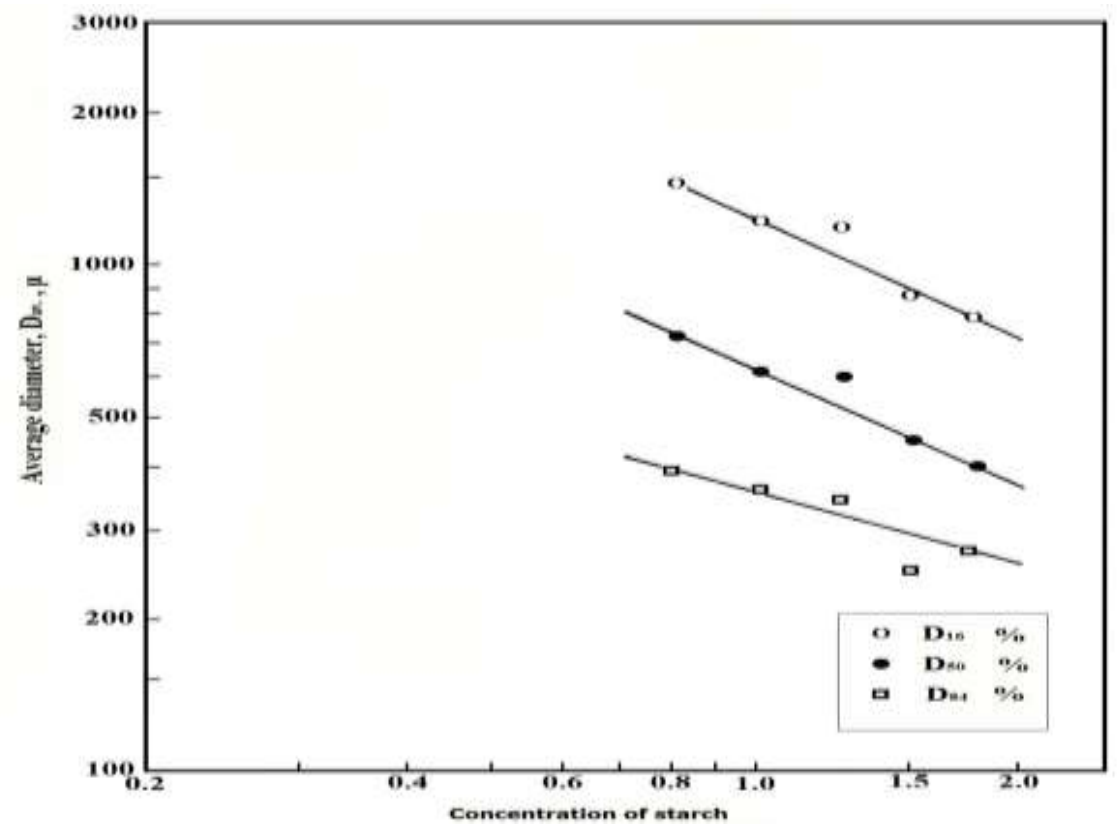

Fig. 9. Log average diameter as function of log concentration of starch at $580 \mathrm{rpm}$.

It is shown that $\log \mathrm{D}_{16 \%}, \log \mathrm{D}_{50 \%}$ and $\log \mathrm{D}_{84 \%}$ are inversely proportional to $\log \mathrm{C}$ and the relation may be governed by the equation:

$$
\log \mathrm{D}=\mathrm{G}+\mathrm{H} \log \mathrm{C}
$$

where $\mathrm{G}$ and $\mathrm{H}$ are constants depending on $\mathrm{N}$.

Graphical analysis data:

It had been concluded that:

$\log \mathrm{D}_{16 \%}=\mathrm{A}+\mathrm{B} \log \mathrm{N}$

$\log \mathrm{D}_{50 \%}=\mathrm{A}^{\prime}+\mathrm{B}^{\prime} \log \mathrm{N}$

$\log \mathrm{D}_{84 \%}=\mathrm{A}^{\prime \prime}+\mathrm{B}^{\prime \prime} \log \mathrm{N}$

where $\mathrm{A}, \mathrm{A}^{\prime}, \mathrm{A}^{\prime \prime}, \mathrm{B}, \mathrm{B}^{\prime}$, and $\mathrm{B}^{\prime \prime}$ are constants depending on $\mathrm{C}$,

Also,

$\log \mathrm{D}_{16 \%}=\mathrm{G}+\mathrm{H} \log \mathrm{C}$

$\log \mathrm{D}_{50 \%}=\mathrm{G}^{\prime}+\mathrm{H}^{\prime} \log \mathrm{C}$

$\log \mathrm{D}_{84 \%}=\mathrm{G}^{\prime \prime}+\mathrm{H}^{\prime \prime} \log \mathrm{C}$

where $\mathrm{G}, \mathrm{G}^{\prime}, \mathrm{G}^{\prime \prime}, \mathrm{H}, \mathrm{H}^{\prime}$, and $\mathrm{H}^{\prime \prime}$ are constants depending on $\mathrm{N}$.

Solution of these equations, by getting values of $\mathrm{A}, \mathrm{A}^{\prime}, \mathrm{A}^{\prime \prime}, \mathrm{B}, \mathrm{B}^{\prime}$, and $\mathrm{B}^{\prime \prime}$ as function of $\mathrm{C}$ or by getting the values of $\mathrm{G}, \mathrm{G}^{\prime}, \mathrm{G}^{\prime \prime}, \mathrm{H}, \mathrm{H}^{\prime}$, and $\mathrm{H}^{\prime \prime}$ as function of 
$\mathrm{N}$, got an equation correlating $\log \mathrm{D}_{16 \%}, \log \mathrm{D}_{50 \%}$ and $\log \mathrm{D}_{84 \%}$ to both $\log \mathrm{N}$ and $\log \mathrm{C}$.

Plotting A, A', A", B, B', and B" against $\log \mathrm{C}$ as shown in Fig. 11 and 12, it is shown that $\mathrm{A}, \mathrm{A}^{\prime}$, and $\mathrm{A}^{\prime \prime}$ are inversely proportional to $\log \mathrm{C}$ and the relation may be governed by the following equations:

$$
\begin{aligned}
& A=12.8826-17.0664 \log C \\
& A^{\prime}=10.7947-11.1306 \log C \\
& A^{\prime \prime}=7.5059-0.7524 \log C \\
& B=-3.7369+5.8120 \log C \\
& B^{\prime}=-2.8993+3.7104 \log C \\
& B^{\prime \prime}=-1.5994
\end{aligned}
$$

By substitution of the values of $\mathrm{A}, \mathrm{A}^{\prime}, \mathrm{A}^{\prime \prime}, \mathrm{B}, \mathrm{B}^{\prime}$, and $\mathrm{B}^{\prime \prime}$ in the main equation:

$$
\begin{aligned}
& \log \mathrm{D}_{16 \%}=\mathrm{A}+\mathrm{B} \log \mathrm{N} \\
& \log \mathrm{D}_{50 \%}=\mathrm{A}^{\prime}+\mathrm{B}^{\prime} \log \mathrm{N} \\
& \log \mathrm{D}_{84 \%}=\mathrm{A}^{\prime \prime}+\mathrm{B}^{\prime \prime} \log \mathrm{N}
\end{aligned}
$$

The following empirical equations were obtained:

$$
\begin{aligned}
& \log \mathrm{D}_{16 \%}=12.8826-17.0664 \log \mathrm{C}-3.7369 \log \mathrm{N}+5.8120 \log \mathrm{N} \log \mathrm{C} \ldots \\
& \log \mathrm{D}_{50 \%}=10.7947-11.1306 \log \mathrm{C}-2.8893 \log \mathrm{N}+3.7104 \log \mathrm{N} \log \mathrm{C} \ldots \\
& \log \mathrm{D}_{84 \%}=7.5059-0.7524 \log \mathrm{C}-1.5994 \log \mathrm{N} \ldots \ldots \ldots \ldots \ldots \ldots \ldots \ldots \ldots \ldots \ldots \ldots \ldots \ldots \ldots \ldots \ldots \ldots
\end{aligned}
$$

\section{Conclusion}

In suspension polymerization of methyl methacylate using starch as protective colloid at $0.75-1.75 \%$ concentration and at any speed of agitation between $400-900 \mathrm{rpm}$ the relation between the particle size of the product, the concentration of starch and the speed of agitation may be governed by the equations 1,2 , and 3 .

Though in the previous article of the same authors ${ }^{(21)}$ found the particle size was directly proportional to speed of agitation in $1 / 4$ liter capacity reactor. The contradiction of the result of this article can be interpreted by the increase of the capacity of the reactors such that the water will absorb the heat of polymerization efficiently, accordingly the breakage of the globules prevails their coalescence.

\section{References}

1. Jahanzad, F., Evaluation of particle size distribution in suspension polymerization reactions, Loughbrough university institutional repository, Chemical Engineering, PhD Theses (2004).

2. Abedin, R., M.Sc., Effect of process mixing on the size distribution and mean diameter of the thiol-triacrylate microcapsules, A Master Thesis in chemical Engineering submitted to Louisiana State University ( 2014).

Egypt. J. Chem. 58, No. 4 (2015) 
3. Renkeez, T., Novel molecularly imprinted polymers-membranes, microspheres, and photoswitchable particles, Ph.D Thesis submitted to Faculty of Chemical Technology and Biotechnology, Budapest University of Technology and Engineering (2013).

4. Valle, A., Microporous polymers beads for chemical decontamination of organophosphorours nerve agents, M.Sc. Thesis submitted to Institute for Kjemi Biotechnologyog Matvitenskap, Norges mijie og Univ.(2014).

5. Santos, A.F., Lima, J.C. and Pinto, Control and design of average particle size of styrene. J. Appl. Polym. Sci. 70 (9), 1737-1745 (1998).

6. Kar P.L. and Christopher, K.O., Particle size control in dispersion polymerization of polystyrene. Canadian Journal of Chemistry, 63(1), 209-216 (1985).

7. Dowding, P.J. and Vincent, B., Suspension polymerization to form polymer beads. Colloids Surf. A, 16, 259 (2000).

8. Özkaya N., Erbay, E., Bilgic,T. and Savasci, O“.T., Agitation scale-up model of engineering for suspension polymerization of poly vinyl chloride. Makromolekular Materials and Engineerieng, 211(1), 35-51 (1993).

9. ASTM Specifications, Standard test methods for particle size sieve analysis of plastic materials, D1921 (1989).

10. ASTM Specifications, Standard test methods for particle size sieve analysis of plastic materials, D1921 (1963).

11. Polacco,G., Palla, M. and Semino, D., Measurements of particle size distribution during suspension polymerization. Polym. Int. 48 (5), 392-397 (1999).

12. Santos, A.F., Lima, E.T. and Pinto, J C., In-line evaluation of average size in styrene using infra red spectroscopy suspension polymerization. J. Appl. Polym. Sci. 77 (2), 453-462. Hukkanen, E.J. and Braatz R.D., Measurement of particle size distribution in suspension polymerization using in situ laser backscattering. Sensors and Actuators, B96, 451-459 (2003).

13. Kamiyama, M., Koyama, K., Matsuda, H. and Sano, Y.J., Micron sized polymer microsphere by suspension polymerization. App. Polym. Sci. 50 (1), 107-113 (1993).

14. Yang, B., Kamidate, Y., Takahashi, B.K. and Takeishi, M., Under unsteady stirring condition of styrene in suspension polymerization. J. Appl. Sci. (7), 14311438 (2000).

15. Mikos, A.G., Takoudis, C.G. and Peppas, N.A., Reaction engineering aspects of suspension polymerization. J. Appl. Polym. Sci. 31 (8), 2647- 2659 (1986).

16. Maggioris, D., Goulasa Alexopoulos, A.H. and Chatzi, E.G., Prediction of particle size distribution in suspension polymerization of reactors: Effect of turbulence nanomgneity. Chem. Eng. Sci. 55 (20), 4611-4627 (2000). 
17. Hounsloue, M.J. and Ni, X., Population balance modeling of droplet coalescence and break up of an oscillatory baffled reactor. Chemical Engineering Science, 59 (4), 819828 (2004).

18. Chen, Z., Pauer, W., Moritz, H.U., PrÜss, J. and Warnecke., H.J., Modelling of the suspension polymerization using a particle population balance. J Chem. Eng. Technol. 22 (7), 609-616 (1999).

19. Yang, B., Takahashi K. and Takeishi M., In-line evaluation of average particle size in styrene. J. Appl. Polym. Sci. 82, 1873-1881 (2001).

20. Barkany I. A., Nemeth, S. and Laktos, B.G., Modeling and simulation of a batch poly (vinyl chloride) reactor. Chemical Engineering Transactions, 32, 769-774 (2013)

21. Abu-Ayana , Y.M. and Mohsen, R.M., Study of some variables affecting particle size and particle size distribution of suspension polymerization of methyl methacrylate. Polymer-Plastic Technology and Engineering, 44,1503-1522 (2005).

22. Langner, F., Mortiz H.U. and Reichert, K.H., Styrene based plastics and their modification. Ger. Chem. Eng. 2, 329 (1979)

23. Tanaka, M. and Hosogai,K., Suspension polymerization with circular loop. J. Appl. Polym. Sci., 39 (4), 955-966 (1990).

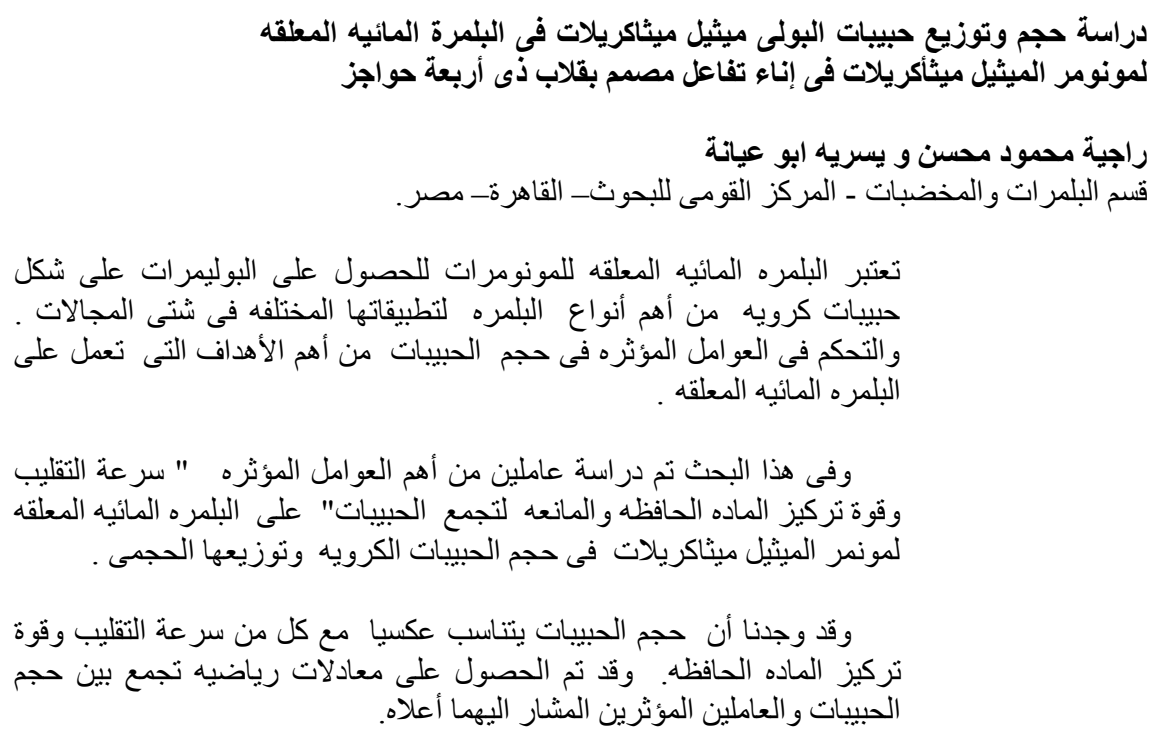

Egypt. J. Chem. 58, No. 4 (2015) 